\title{
Desafios e gratificações do Ensino de Jovens e Adultos na Formação de educadoras feirenses de 1990 à 2000
}

\author{
Beatriz Santos da Silva ${ }^{1}$; Irlana Jane Menos da Silva ${ }^{2}$ \\ 1. Bolsista PIBIC/Fapesb, Graduanda em Licenciatura em História, Universidade Estadual de Feira de Santana, \\ email: bia_santos999@hotmail.com \\ 2. Orientadora, Departamento de Educação, Universidade Estadual de Feira de Santana, e-mail: \\ irlanamenas@ hotmail.com
}

PALAVRAS-CHAVE: Educação. EJA. Mulheres.

\section{INTRODUÇÃO}

A história educacional brasileira, desde seu início baseou-se em uma forma de controle, dominação social, e em uma sucessão de reformas constantes. É possível avaliar esse tipo de utilização como política de domínio, principalmente através das fases coloniais: domínio jesuítico 1549-1759 (religião e educação), reformas pombalinas (1758) e período joanino, a partir de 1808, com a chegada da Família Real e Corte Portuguesa para o Brasil. Ao longo do tempo de formalização desse ensino, no que se referia ao ensino básico e principalmente ensino superior, esses recursos eram privilégios das elites, pois, existiam poucas políticas, ainda incompletas, e praticamente nenhum interesse público que abarcasse segmentos da população que não possuía condições financeiras ou tempo para os estudos. É claro que escravos, mulheres livres e sujeitos das camadas subalternas estavam alijados do processo.

É possível identificar a problemática das minorias, que são também parte dessa exclusão. Neste momento, entra a figura das mulheres como educadoras, sujeitos do nosso tema principal de pesquisa, e todas as lidas diárias que dialogam juntamente com sua formação profissional. E como Simone de Beauvoir, diz: "Ninguém nasce mulher, torna-se mulher", é possível problematizar o espaço social dado a ela desde os primórdios da história humana, como por exemplo, Eva, dita a primeira mulher da humanidade, segundo a Bíblia. Quando citamos essa frase não estamos falando de um fator biológico, e sim de toda uma necessidade constante de reafirmação social do ser mulher, se ela quiser lutar por um espaço que lhe é geralmente negado. E, então, a educação da mulher chega não somente como uma profissão, mas também como uma manifestação de luta por espaços públicos, antes só admitidos aos indivíduos do sexo masculino. Nesse sentido, reconhecemos que esse avanço compôs um arcabouço necessário à construção intelectual e conscientização de muitas mulheres, que passaram a brigar pela conquista de novos direitos.

Em uma perspectiva pessoal, coloco em diálogo com essas educadoras, o EJA (Ensino de Jovens e Adultos) que é um programa que atende aqueles que por algum motivo não concluíram seus estudos na faixa etária prevista por lei.

O Programa EJA representa, portanto,

[...] Um poderoso argumento em favor do desenvolvimento ecológico sustentável, da democracia, da justiça, da igualdade entre os sexos, do desenvolvimento sócio econômico e científico, além de um requisito fundamental para a construção de um mundo onde a violência cede lugar ao diálogo e a cultura de paz baseada na justiça. (UNESCO, 1997: Hamburgo, Alemanha, sobre o EJA).

Os percalços aqui apresentados, também se encontram no ensino regular, porém, tendo um conhecimento da dinâmica desse ambiente, através de uma participante desse projeto, fui inquietada a partir de uma curiosidade sobre como se dão essas relações professor/aluno (a), e no campo mais específico, educadora/aluno (a), e quais as trocas de experiências, que podem contribuir principalmente para a formação da própria educadora. 


\section{MATERIAL E MÉTODOS OU METODOLOGIA (ou equivalente)}

Para realização da pesquisa utilizamos referenciais bibliográficos que compõem o projeto EDUCADORAS BAIANAS: SABERES E EXPERIÊNCIAS DE PRÁTICAS PEDAGÓGICAS DE PROFESSORAS DA EDUCAÇÃO BÁSICA NO SÉCULO XX e que foram disponibilizados pelo grupo de estudos e pesquisas em história, educação e gênero - GEPHEG, documentos das educadoras que já ministraram aulas na EJA e entrevistas com estas mulheres, pois para entender o contexto pesquisado, é necessário também entender as minorias e fatos não identificados como primordiais, através da história de vida das educadoras. Para isso, entrevistamos duas educadoras, com idades de 50 e 60 anos respectivamente, sendo que uma está em exercício docente, mas não atua no EJA atualmente e a outra está aposentada. Contactamos com as entrevistas a partir de indicação de outras educadoras marcamos a entrevista para conversa sobre a pesquisa e depois efetuamos as entrevistas de acordo com o tempo e horários disponibilizados pelas educadoras.

\section{RESULTADOS E/OU DISCUSSÃO (ou Análise e discussão dos resultados)}

$\mathrm{Na}$ análise dos resultados obtidos pelas entrevistas com as quatro educadoras, desenvolvi duas categorias, dentre as quais destaco:

\subsection{AS POSSIBILIDADES EDUCATIVAS COM AS DIVERSAS FAIXAS ETÁRIAS}

Primeiramente jovens e adultos não podem ser tratados como crianças. São pessoas que não tiveram infância, ou tiveram uma infância frustrada, têm vergonha de si mesmos, possuem complexos de inferioridade diante da sociedade que os oprime e os discrimina (FREIRE, 1987).

P1: A diferença eu só vim perceber realmente quando eu me deparei com os alunos da EJA da zona rural. Por que era uma outra realidade, eram meninos, eram senhoras e senhores, com quarenta, cinquenta, sessenta anos, que nunca tinha ido na escola, e ainda eles não se chamavam pelo primeiro nome, sempre por apelido, era muito complexo[...] Um grande desafio. Foi uma loucura. Era uma loucura, uma dificuldade, e havia uma problemática, eu tinha vindo de escola particular, como eu tinha vindo de escola particular, eu acreditava que o que eu tinha aprendido, o que eu tinha trabalhado em escola particular, dava certo, mas não dava certo. E lá, nós tínhamos alunos de trinta, quarenta, cinquenta, sessenta anos, mas eu tinha aluno de dezessete anos. Então, era uma diversidade muito grande, e você tinha que se virar, enquanto profissional de educação pra dar conta de todo mundo e fazer com que sua aula fosse interessante.

P2: Muito bom, a troca de experiências né?! Na época também, ainda tinha-se mais respeito pela pessoa com mais idade. E também porque eu sempre estava conversando com meus alunos a respeito deles estarem ali, numa idade mais avançada, ou deles estarem ali, numa idade ainda tão jovem e já estar frequentando uma escola noturna. Sempre havia um motivo pelo qual, ou o adulto ia muito atrasado, ou um jovem estava ali quando ele podia estar cursando uma escola durante o dia.

No discurso das professoras está implícito que enfrentaram adversidades em relação às diferenças etárias, apontadas pelas educadoras, que também produzia diferenças culturais. A 
abordagem de temas transversais na EJA depende de muitos fatores, como a concepção da educadora, as demandas de cada turma e o modo como se dão essas relações, assim como também uma educação com um público mais próximo da cidade (Professora 2) e um público rural (Professora 1).

De acordo com os conteúdos que as educadoras atuavam fica claro que havia uma diversidade de temáticas da representação social conforme gênero, religião e que não havia necessidade de abrir a discussão sobre estes temas, pois o respeito era mantido.

P1: Essa coisa de conteúdos transversais, de homossexualidade, essa coisa não era coisa que se falava na época, primeiro não se falava e também, nós tínhamos meninos, tinha colega que era evangélico, tinha o outro que era do candomblé, mas não havia preconceito por conta de que eles se conheciam há muitos anos. Havia um que era homossexual, mas era um homossexual muito contido, e eles não tinham preconceito em relação a isso, eram coisas que não se falavam porque não havia necessidade. Mas assim, havia um respeito muito grande, muito grande entre eles e passou a ter comigo a partir do momento...Que como dizia...Vando dizia assim pra mim, que quando eu comecei a trabalhar com eles, Vando é "Fumo". Fumo disse "Papagaio veio não aprende a falar", quando no segundo ano ele disse "É, a senhora fez um papagaio velho falar".

P2: As oportunidades surgem, é... Muitas vezes, muitas vezes, eu abria assim pra eles, o que é que eu gostaria de estar colocando pra eles, e pedia pra eles que escolhessem algum tema, então escolhido o tema, nós começávamos então a pesquisar, tanto eu, como eles, e então abríamos discussão sobre os vários assuntos né?! Homofobia, sobre racismo, sobre religião. [...] Olha, eu tinha.... Tínhamos na escola, no geral, testemunha de Jeová, adventistas, outras religiões também protestantes, não lembro mais, mas tínhamos também católicos, a maioria, e tínhamos também pessoas voltadas ao candomblé.[...] eu acho que nós estamos em uma sala de aula, para viver essa diversidade, e o professor ele deve conversar com seus alunos sobre a diversidade e o respeito que se deve ter com o outro. Eu sou católica, mas convivo muito bem com qualquer religião, o Deus é único, em todas as religiões, pelo menos nas religiões cristãs e não cristã... Até mesmo o candomblé acredita em Deus né?! Então por que brigar por isso? Sempre orientei, sempre discutimos sobre religião e ficava muito claro que todos nós deveríamos respeitar a diversidade.

Há que se preocupar com o cidadão que busca a EJA nos diferentes espaços, tanto na cidade, como no meio rural, pois as formas de ensinar se constituem em desafios, considerando o compromisso social e profissional com a comunidade. (BENITE; FRIEDRICH; PEREIRA). Mesmo com as diferenças, o respeito é um elemento citado com grande importância para as relações cotidianas entre os estudantes e os professores.

\section{CONSIDERAÇÕES FINAIS (ou Conclusão)}


Através das entrevistas, juntamente com a análise e leitura do material bibliográfico, foi possível identificar os desafios e gratificações no Ensino de Jovens e Adultos na década de 90, período em que a infraestrutura, aporte teórico a material didático era insuficiente, mas ainda assim não foi empecilho suficiente para educadoras engajadas e comprometidas com a educação.

\section{REFERÊNCIAS}

ALMEIDA, Stela Borges de. BARROS, Maria Lêda Riebeiro. Implantação Da Escola Primária Baiana: Relendo Satyro Dias e Anísio Teixeira - 1893-1928

CRUZ, Antônio Roberto Seixas da; RIBEIRO, Marinalva Lopes.Flores do Sertão: Perfilando professoras formadas pela Escola Normal De Feira De Santana De 1930 A 1949. Dispoível em <http://www.histedbr.fe.unicamp.br/revista/edicoes/36/art14_36.pdf >

CRUZ, Antonio Roberto Seixas.Mestras no Sertão: reconstituindo caminhos

percorridos. Salvador, 2000.

FREIRE, Paulo. Pedagogia da Esperança: um reencontro com a pedagogia do oprimido. São Paulo: Paz e Terra, 1992.

FREIRE, Paulo. Política e educação: ensaios- 5. ed - São Paulo, Cortez, 2001. (Coleção Questões de Nossa Época; v.23)

IRELAND, Timothy. Anotações sobre a educação em prisões: direito, contradições e desafios. Brasília: Unesco, 2008.

Disponível em 〈http://www.gestaoemacao.ufba.br/revistas/ga\%20912006-DlealRosa.pdf>

MAGAlHÃES, Lívia Diana Rocha.A Educação da Primeira República, 2004. Disponível em <http://www.histedbr.fe.unicamp.br/navegando/artigos_pdf/Livia_D_Rocha_Magalhaes_artigo.p $\underline{\mathrm{df}}>$

RIBEIRO, Maria Luisa Santos. História da Educação Brasileira: a educação escolar - 12 -. Ed. São Paulo: Cortez: Autores Associados, 1992

SAVIANI, Dermeval. Escola e democracia: teorias da educação, curvatura da vara, onze teses sobre educação e política. 32. ed.- Campinas, SP: AutoresAssociados, 1999. - (Coleção polêmicas do nosso tempo; v.S)

SAVIANI, Dermeval. Política Educacional Brasileira: Limites e Perspectivas - Revista de Educação Puc-Campinas, Campinas, n. 24, p. 7-16, Junho 2008 Disponível em <http://www.aedi.ufpa.br/parfor/letras/images/documentos/ativ2_2014/breves/breves2012/poltica \%20educacional\%20brasileira\%20limites\%20e\%20perspectivas.pdf $>$

SILVA, M. C O ensino primário na Bahia: 1889- 1930. Tese (Doutorado em Educação). Salvador: Faculdade de Educação - Universidade Federal da Bahia, Bahia.1997.Disponível em <http://www.ppgh.ufba.br/wp-content/uploads/2013/10/Um-Olhar-Sobre-a-

Educa\%C3\%A7\%C3\%A3o-na-Bahia.pdf>

SOARES, Leôncio. O educador de jovens e adultos e a sua formação. Educação em Revista | Belo Horizonte | n. 47 | p. 83-100 | jun. 2008

SOUSA, Ione Celeste de. Garotas tricolores, deusas fardadas: as normalistas em Feira de Santana, 1925 a 1945 - São Paulo: EDUC, 2001. 197p

VILLELA, Heloísa de O. S. O mestre-escola e a professora. In: LOPES, Eliane M. T.; FARIA FILHO, Luciano M.; VEIGA, Cynthia G. (Orgs.). 500 anos de Educação no Brasil. 3.ed. Belo Horizonte: Autêntica, 2003. 